\title{
The tumour necrosis factor (TNF)- $\alpha$ system is activated in accordance with pulse pressure in normotensive subjects with type 1 diabetes mellitus
}

J M González-Clemente, G Giménez-Pérez, C Richart ${ }^{1}$, M Broch ${ }^{1}$, A Caixàs, A Megia ${ }^{1}$, O Giménez-Palop, I Simón ${ }^{1}$. D Mauricio and J Vendrell ${ }^{1}$

Department of Diabetes, Endocrinology and Nutrition, Hospital de Sabadell, Sabadell, Spain ${ }^{1}$ Diabetes and Research Unit, Hospital Universitari de Tarragona Joan XXIII, Universitat Rovira i Virgili, Spain

(Correspondence should be addressed to J-M González-Clemente, Department of Diabetes, Endocrinology and Nutrition, Hospital de Sabadell, Parc Taulí s/n, 08208 Sabadell, Spain; Email: jmgonzalez@cspt.es)

\begin{abstract}
Objective: Pulse pressure (PP) and inflammation are important predictors of cardiovascular disease (CVD), even in the normotensive. The age-related increase in PP can be diagnosed up to 20 years earlier in subjects with type 1 diabetes mellitus (T1DM) than in the general population. Some evidence suggests that PP can stimulate inflammation. Our aim was to study the relationship between PP and plasma inflammatory proteins in normotensive subjects with T1DM.

Design: This was a cross-sectional study of a group of normotensive $(<140 / 80 \mathrm{mmHg})$ subjects diagnosed with T1DM 14 years before. None of them had clinically proven CVD or inflammatory conditions or were on antiplatelet, antihypertensive, anti-inflammatory or lipid-lowering treatment. Methods: The following information was recorded: sex, age, body-mass index (BMI), waist-to-hip ratio (WHR), systolic blood pressure (SBP), diastolic blood pressure (DBP), PP, mean blood pressure (MBP), smoking, alcohol intake, insulin dose, lipid profile, HbAlc, microvascular complications, and plasma concentrations of soluble receptor types 1 and 2 of tumour necrosis factor (TNF)- $\alpha$ (sTNFR1 and sTNFR2, respectively), interleukin-6, C-reactive protein, adiponectin and leptin.

Results: A total of 112 subjects were evaluated (aged 27.4 \pm 6.6 years, $52.7 \%$ women, BMI: $20.4 \pm 2.7 \mathrm{~kg} / \mathrm{m}^{2}$, WHR: $0.82 \pm 0.09$, SBP: $112 \pm 12 \mathrm{mmHg}$, DBP: $68 \pm 9 \mathrm{mmHg}, \mathrm{PP}: 45 \pm 9 \mathrm{mmHg}$, MBP: $82 \pm 9 \mathrm{mmHg}$, HbA1c: $8.2 \%$ (7.3-9.0\%), 41.1\% microvascular complications). After adjusting for potential confounders, only inflammatory markers of the TNF- $\alpha$ system correlated significantly with PP (Pearson correlation coefficient between sTNFR1 and PP: $r=0.215, P=0.030$; and between PP and sTNFR2: $r=0.238, P=0.020$ ).

Conclusion: In normotensive subjects with T1DM after 14 years of diagnosis, the activation of the TNF- $\alpha$ system is positively associated with PP levels. This finding might suggest a pathogenic role of the TNF- $\alpha$ system in the development of cardiovascular disease in T1DM.
\end{abstract}

European Journal of Endocrinology 153 687-691

\section{Introduction}

Subjects with type 1 diabetes mellitus (T1DM), even those younger than 30 years, have an extra risk of cardiovascular disease (CVD) $(1,2)$. Inflammation has recently been recognized as a predictor of CVD (3), and CVD has also been associated with the score of three inflammatory markers (tumour necrosis factor (TNF)- $\alpha$, interleukin-6 (IL-6) and C-reactive protein (CRP)) in subjects with T1DM (4). In addition, pulse pressure (PP), which increases with ageing as a consequence of arterial stiffness (5), is another predictor of CVD (6). In particular, it is a predictor of CVD mainly over the age of 50 years (7), even in normotensive subjects (8). In subjects with T1DM, the age-related increase in PP levels can be diagnosed up to 20 years before, even in subjects without nephropathy (9), and it is also associated with CVD (10). In addition, in young subjects with T1DM, an increase in arterial stiffness has also been described $(11,12)$, suggesting a pathogenic role in the early increase of PP in T1DM.

There is some evidence that an increase in PP may stimulate inflammation, suggesting that one of the mechanisms underlying the link between elevated PP and increased CVD risk may be inflammation (13-15). If the link between PP and CVD risk is indeed mediated by inflammation and operates in subjects with T1DM, one would expect to see positive 
associations between $\mathrm{PP}$ and markers of systemic inflammation that are predictive of CVD risk, such as TNF- $\alpha$, IL-6 or CRP. To gain some insight into the role of inflammation and $\mathrm{PP}$ in the pathogenesis of CVD in T1DM, we thought it worthwhile to analyse their relationship in a group of normotensive subjects with T1DM after 14 years of evolution. In addition to the above-mentioned inflammatory markers previously associated with CVD, we also explored the relationship between $\mathrm{PP}$ and other plasma proteins, which have more recently been associated positively (leptin) (16) or negatively (adiponectin) with CVD (17).

\section{Subjects and methods}

\section{Subjects}

A group of normotensive $(<140 / 80 \mathrm{mmHg})$ subjects with T1DM, all having been diagnosed 14 years before (18), were recruited. None of them had any condition that increased plasma inflammatory markers (such as acute or chronic inflammatory, or infectious, diseases) or had received antiplatelet, antihypertensive, antiinflammatory or lipid-lowering treatment. None of them had clinically proven CVD (angina pectoris, myocardial infarction, intermittent claudication, amputation or stroke). The study protocol was approved by the local ethics committee and was conducted according to the principles of the Declaration of Helsinki. All subjects gave their informed consent before participating in the study and were evaluated after an overnight fast and before administering the morning insulin injection. Venous blood samples were drawn, and aliquots of plasma and serum were stored at $-70^{\circ} \mathrm{C}$ until processing. The following information was collected with a predefined, standardized form: sex, age, body-mass index (BMI), waist-to-hip ratio (WHR), systolic blood pressure (SBP), diastolic blood pressure (DBP), PP, mean blood pressure (MBP), smoking, alcohol intake, insulin dose, lipid profile, HbAlc, microvascular complications, and plasma concentrations of soluble receptor types 1 and 2 of TNF- $\alpha$ (sTNFR 1 and sTNFR 2 respectively), IL-6, CRP, adiponectin and leptin.

\section{Anthropometric measurements}

Height was measured to the nearest $0.5 \mathrm{~cm}$ and body weight to the nearest $0.1 \mathrm{~kg}$. BMI was calculated as weight (in $\mathrm{kg}$ )/height (in $\mathrm{m}^{2}$ ). Waist circumference was measured midway between the lower rib margin and the iliac crest. Hip circumference was determined as the widest circumference measured over the greater throcanter. WHR was then calculated. After subjects rested for at least $5 \mathrm{~min}$, blood pressure was measured twice in a sitting position with a mercury sphygmomanometer. SBP was recorded at phase I and DBP at phase $\mathrm{V}$ of Korotkoff sounds. The mean of the two recordings was used in the study. PP was calculated as the difference between SBP and DBP, and MBP as one-third of SBP plus two-thirds of DBP.

\section{Analytical methods}

HbA1c was determined in capillary blood by immunoassay (DCA 2000, Bayer AG, Zurich, Switzerland). Total serum cholesterol, triglycerides and high-density lipoprotein (HDL) cholesterol were measured by standard enzymatic methods. Low-density lipoprotein (LDL) cholesterol was estimated by the Friedewald formula (19). Plasma sTNFR1 and sTNFR2 were determined by a solid-phase, enzyme-amplified, sensitivity immunoassay (Medgenix sTNFR1-EASIA, sTNFR2-EASIA; BioSource Europe, Fleurus, Belgium); plasma IL-6 by an ultrasensitive, solid-phase enzymoimmunoassay (Biosource, Nivelles, Belgium); plasma CRP by a highly sensitive immunonephelometry kit (Dade Behring, Marburg, Germany); and plasma adiponectin and leptin by RIA (Linco Research, St Charles, MO, USA).

\section{Assessment of microvascular complications}

The assessment of all microvascular complications was blind to the clinical characteristics of the subjects. Retinal photographs of the macular field were taken of each eye with a non-mydriatic retinal camera (CR6-45NM; Canon, Lake Success, NY, USA) by an experienced endocrinologist An ophthalmologist assessed all these photographs and classified them into three categories according to the degree of retinopathy in the worst eye: no retinopathy, non-proliferative retinopathy and proliferative retinopathy. Proliferative retinopathy was defined as the presence of new vessels, fibrous proliferations, preretinal haemorrhage, vitreous haemorrhage or photocoagulation scars. Any other lesion was classified as a non-proliferative retinopathy. The level of urinary albumin excretion was evaluated as previously recommended (20), using urinary samples obtained during the study. Subjects with a ratio greater than $30 \mathrm{mg}$ albumin/g creatinine were considered to have diabetic nephropathy.

To establish the presence of diabetic peripheral neuropathy, we used a two-step protocol. The first step consisted of a 15-item MNSI questionnaire (21). The second step consisted of a quantitative neurological examination of the lower extremities (22), including assessment of the following: 1. pressure perception using a 5.07/10 g Semmes-Weinstein monofilament; 2. vibratory perception using a $128 \mathrm{~Hz}$ tuning fork with the on-off method; 3. superficial pain sensation with a sterile tip; 4 . ankle and knee reflexes. The presence of diabetic peripheral neuropathy was defined by a MNSI questionnaire score of $>7$ plus an alteration in any of these four neurological examinations. Cardiovascular autonomic neuropathy was studied by the following three tests: 1 . heart rate variation in response to deep breathing; 2. heart rate variation in response to 
the Valsalva manoeuvre; 3. SBP changes on standing after resting in the horizontal position for at least 5 min (23). The response to each of these tests was categorized as normal, borderline, or abnormal by a portable computerized system (Cardionomic; Medimatica, Martinsicuro, Italy) (24). Cardiovascular autonomic neuropathy was defined as an abnormality in at least one of these three tests.

\section{Statistical analyses}

To improve skewness and kurtosis, variables not normally distributed were log transformed. Multiple linear regression analyses were carried out to assess the relationships between blood pressure indexes and inflammatory markers, adjusting for potential confounders. The SPSS/PC + statistical program (Version 11.5 for Windows; Chicago, IL, USA) was used. All $P$ values were two-sided, and a $P$ value of $<0.05$ was considered statistically significant.

\section{Results}

A total of 112 subjects were evaluated, 46 of them with one or more microvascular complications. Their main clinical and analytical characteristics are shown in Table 1. Table 2 shows the unadjusted and adjusted

Table 1 Clinical characteristics of the subjects with type 1 diabetes mellitus (TIDM) included in the study.

\begin{tabular}{|c|c|}
\hline & $\begin{array}{l}\text { Subjects with TIDM } \\
\qquad(n=112)\end{array}$ \\
\hline Sex (\% of women) & 52.7 \\
\hline Age (years) & $27.4 \pm 6.6$ \\
\hline BMI $\left(\mathrm{kg} / \mathrm{m}^{2}\right)$ & $20.4 \pm 2.7$ \\
\hline Waist-hip ratio & $0.82 \pm 0.09$ \\
\hline Systolic blood pressure $(\mathrm{mmHg})$ & $112 \pm 12$ \\
\hline Diastolic blood pressure $(\mathrm{mmHg})$ & $68 \pm 9$ \\
\hline Pulse pressure $(\mathrm{mmHg})$ & $45 \pm 9$ \\
\hline Median blood pressure $(\mathrm{mmHg})$ & $82 \pm 9$ \\
\hline Current smokers (\%) & 68.9 \\
\hline Current alcohol intake > $20 \mathrm{~g} /$ day (\%) & 21.4 \\
\hline Insulin dose ((IU/day) & $49.7 \pm 16.3$ \\
\hline Cholesterol $(\mathrm{mmol} / \mathrm{l})$ & $4.92 \pm 0.8$ \\
\hline Triglycerides $(\mathrm{mmol} / \mathrm{l})$ & $1.46 \pm 0.38$ \\
\hline HDL cholesterol $(\mathrm{mmol} / \mathrm{l})$ & $0.84(0.62-1.17)$ \\
\hline LDL-cholesterol (mmol//) & $3.02 \pm 0.69$ \\
\hline HbAlc (\%) & $8.2(7.3-9.0)$ \\
\hline Retinopathy & 16.1 \\
\hline Nephropathy & 3.6 \\
\hline Peripheral neuropathy & 25.0 \\
\hline Cardiovascular autonomic neuropathy & 6.3 \\
\hline sTNFR1 $(\mathrm{ng} / \mathrm{ml})$ & $2.09 \pm 0.69$ \\
\hline sTNFR2 (ng/ml) & $4.27 \pm 1.14$ \\
\hline IL-6 (pg/ml) & $0.84(0.60-1.25)$ \\
\hline hsCRP (mg/dl) & $0.95(0.46-2.49)$ \\
\hline Adiponectin (mg/l) & $11.11(8.47-15.92)$ \\
\hline Leptin (ng/ml) & $10.85 \pm 7.44$ \\
\hline
\end{tabular}

All values are given as percentages, means \pm S.D. or medians (interquartile range). correlations between blood pressure indexes and plasma inflammatory proteins. Of all the evaluated inflammatory proteins, only those associated with the activation of the TNF- $\alpha$ (sTNFR1 and sTNFR2) were associated with some of the evaluated blood pressure indexes. In particular, after adjusting for potential confounders, we found a positive relationship between sTNFR 1 and PP $(r=0.215 ; P=0.030)$. This relationship would be explained mainly through the positive relationship between sTNFR1 and SBP, since SBP and PP were obviously highly correlated $(r=0.656$; $P=0.001)$. In addition, we also found a positive relationship between sTNFR2 and PP $(r=0.238$; $P=0.020$ ), although in this case this association would not be explained by a positive relationship between sTNFR 2 and SBP $(r=0.091 ; P=0.372)$.

\section{Discussion}

To our knowledge, this is the first study showing that PP is associated with activation of the TNF- $\alpha$ system in normotensive subjects with T1DM. This association remains unchanged after adjusting for potential confounders, such as microvascular complications (including nephropathy). In addition, no other proinflammatory (IL-6, CRP, leptin) or anti-inflammatory (adiponectin) plasma proteins are associated with any of the evaluated blood pressure indexes in these subjects.

The main finding of the present study is that PP is associated with an activation of the TNF- $\alpha$ system, measured through the plasma concentrations of sTNFR1 and sTNFR2. It is thought that sTNFR1 and sTNFR2 may better reflect longer-term average levels of TNF- $\alpha$ than TNF- $\alpha$ itself $(25,26)$. In contrast to STNFR1, sTNFR2 is more closely associated with the metabolic effects of TNF- $\alpha$ (27). In this study, both sTNFR1 and sTNFR2 were positively associated with PP levels. The association between sTNFR1 and PP would be explained mainly through the systolic component of PP, because a positive relationship was also found between sTNFR 1 and SBP. However, this was not the case in the association between sTNFR2 and PP, because no significant relationship was found between sTNFR2 and SBP. There is some evidence that increases in PP may stimulate inflammation. In particular, an increase in PP is associated with elevated levels of reactive oxygen species (13), which in turn may stimulate inflammatory signalling pathways $(14,15)$. In addition, higher levels of PP are associated with greater flow reversals during diastole (28), and flow reversals can increase the expression of adhesion molecules (29), which would promote the inflammatory atherosclerotic process.

Apart from CRP, no other inflammatory proteins have previously been evaluated in relation to PP. TNF- $\alpha$ stimulates the synthesis of CRP (30). In apparently healthy adults, elevated non-high-sensitivity CRP plasma concentrations are associated with an increase in PP, 
Table 2 Pearson correlation coefficients between pressure indexes (SBP, DBP, PP and MBP) and evaluated inflammatory markers (sTNFR1, sTNFR2, IL-6, CRP, adiponectin and leptin), unadjusted (first line of each cell), adjusted only for age and sex (second line of each cell) and adjusted for age, sex, BML, smoking alcohol intake, insulin dose, HDL cholesterol, HbAlc, retinopathy, albumin excretion rate, diabetic peripheral neuropathy and cardiovascular autonomic neuropathy (third line of each cell). Only sTNFR1 and sTNFR2 were positively associated with PP levels.

\begin{tabular}{|c|c|c|c|c|c|c|c|c|c|c|}
\hline & SBP & DBP & PP & MBP & sTNFR1 & sTNFR2 & IL-6 & CRP & Adiponectin & Leptin \\
\hline \multirow[t]{3}{*}{ SBP } & 1.0 & $0.500^{*}$ & $0.634^{*}$ & $0.788^{*}$ & 0.207 & 0.232 & -0.137 & -0.133 & -0.261 & -0.093 \\
\hline & & $0.565^{\star}$ & $0.647^{*}$ & $0.827^{*}$ & 0.153 & 0.096 & -0.039 & -0.058 & 0.009 & 0.121 \\
\hline & & $0.523^{*}$ & $0.656^{*}$ & $0.808^{*}$ & 0.219 & 0.091 & -0.026 & -0.075 & 0.090 & 0.028 \\
\hline \multirow[t]{3}{*}{ DBP } & & 1.0 & $0.334^{\dagger}$ & $0.927^{*}$ & -0.049 & -0.014 & 0.100 & 0.054 & -0.145 & 0.043 \\
\hline & & & $-0.249^{\dagger}$ & $0.931^{*}$ & 0.016 & -0.110 & 0.087 & 0.004 & -0.016 & 0.120 \\
\hline & & & $-0.285^{\star}$ & $0.924^{*}$ & 0.042 & -0.141 & 0.153 & -0.007 & -0.013 & 0.058 \\
\hline \multirow[t]{3}{*}{ PP } & & & 1.0 & 0.034 & 0.259 & $0.273^{\dagger}$ & -0.206 & -0.170 & -0.132 & -0.086 \\
\hline & & & & 0.114 & 0.175 & $0.224^{\dagger}$ & -0.112 & -0.064 & 0.034 & 0.049 \\
\hline & & & & 0.094 & $0.215^{\dagger}$ & $0.238^{\dagger}$ & -0.148 & -0.075 & 0.127 & 0.004 \\
\hline \multirow[t]{3}{*}{ MBP } & & & & 1.0 & 0.055 & 0.089 & 0.010 & -0.021 & -0.219 & -0.017 \\
\hline & & & & & 0.075 & -0.034 & 0.043 & -0.023 & -0.009 & 0.132 \\
\hline & & & & & 0.124 & -0.058 & 0.095 & -0.038 & 0.028 & 0.049 \\
\hline \multirow[t]{3}{*}{ sTNFR1 } & & & & & 1.0 & $0.534^{*}$ & 0.014 & 0.029 & 0.098 & -0.013 \\
\hline & & & & & & $0.384^{*}$ & 0.122 & 0.160 & 0.049 & 0.047 \\
\hline & & & & & & $0.349^{*}$ & 0.138 & 0.162 & -0.014 & 0.138 \\
\hline \multirow[t]{3}{*}{ sTNFR2 } & & & & & & 1.0 & 0.113 & 0.064 & 0.110 & 0.000 \\
\hline & & & & & & & 0.128 & 0.152 & 0.152 & -0.004 \\
\hline & & & & & & & 0.138 & 0.176 & 0.135 & 0.048 \\
\hline \multirow[t]{3}{*}{ IL-6 } & & & & & & & 1.0 & $0.432^{*}$ & -0.180 & 0.045 \\
\hline & & & & & & & & $0.413^{*}$ & $-0.252^{\dagger}$ & 0.139 \\
\hline & & & & & & & & $0.414^{\star}$ & -0.224 & 0.162 \\
\hline \multirow[t]{3}{*}{ CRP } & & & & & & & & 1.0 & -0.119 & 0.115 \\
\hline & & & & & & & & & -0.133 & 0.077 \\
\hline & & & & & & & & & -0.104 & 0.031 \\
\hline \multirow[t]{3}{*}{ Adiponectin } & & & & & & & & & 1.0 & 0.106 \\
\hline & & & & & & & & & & -0.006 \\
\hline & & & & & & & & & & 0.163 \\
\hline Leptin & & & & & & & & & & 1.0 \\
\hline
\end{tabular}

${ }^{*} P<0.01 ;{ }^{\dagger} P<0.05$

regardless of SBP and DBP (31). However, we did not find such an association. Our study was performed in a group of subjects with T1DM with little heterogeneity regarding their atherosclerotic burden (14 years of evolution, normotensive, no clinical CVD). Under these circumstances, any possible association between PP and inflammation would tend to be underestimated. However, we cannot exclude that our results may reflect real pathophysiological differences in how these inflammatory proteins relate to CVD in early stages of the atherosclerotic process. Nevertheless, the activation of the TNF- $\alpha$ system seems to be a risk factor for $\operatorname{CVD}(3,32,33)$ and several pathogenic mechanisms have been suggested in this respect $(33-35)$.

Although the findings of the present study suggest that an increase in PP may activate the TNF- $\alpha$ system, other explanations are possible. Firstly, the present study was based on observational data, and confounding from factors that were not controlled for, and/or residual confounding from factors that we did control for but measured inaccurately, may be an alternative explanation for our results. Secondly, the cross-sectional design of the present study makes it impossible to determine the temporal ordering of the association that we observed between PP and the activation of the TNF- $\alpha$ system. Although the above-mentioned evidence suggests that increases in PP would enhance inflammation, we cannot rule out inflammation as a mechanism to increase PP, as has been previously suggested (36). Nevertheless, the present study suggests that mechanisms linking PP and inflammation already operate in normotensive subjects with T1DM, and that the inflammatory mechanism mainly implicated is the activation of the TNF- $\alpha$ system.

In summary, in normotensive subjects with T1DM 14 years after diagnosis, an increase in PP levels is associated with an activation of the TNF- $\alpha$ system. This finding might specifically suggest a pathogenic role of TNF- $\alpha$ system in CVD in T1DM, and argues for future prospective studies to assess the involvement of $\mathrm{PP}$ and the TNF- $\alpha$ system in the pathogenesis of CVD in T1DM.

\section{Acknowledgements}

Financial support was provided by Fondo de Investigaciones Sanitarias (RG03/212, RC03/08), Instituto de Salud Carlos III, Ministerio de Sanidad y Consumo, Spain. We are also indebted to Dr Amparo MartínezRiquelme, Dr Conxa Castell (Consell Assesor sobre la 
Diabetis a Catalunya) and the Board of the Associació Catalana de Diabetis.

\section{References}

1 Laing SP, Swerdlow AJ, Slater SD, Botha JL, Burden AC, Waugh NR, Smith AW, Hill RD, Bingley PJ, Patterson CC, Qiao Z \& Keen H. The British Diabetic Association Cohort Study. II. Cause-specific mortality in patients with insulin-treated diabetes mellitus. Diabetic Medicine 199916 466-471.

2 Laing SP, Swerdlow AJ, Carpenter LM, Slater SD, Burden AC, Botha JL, Morris AD, Waugh NR, Gatling W, Gale EA, Patterson CC, Qiao Z \& Keen H. Mortality from cerebrovascular disease in a cohort of 23000 patients with insulin-treated diabetes. Stroke $2003 \mathbf{3 4} 418-421$.

3 Pai JK, Pischon T, Ma J, Manson JE, Hankinson SE, Joshipura K, Curhan GC, Rifai N, Cannuscio CC, Stampfer MJ \& Rimm EB. Inflammatory markers and the risk of coronary heart disease in men and women. New England Journal of Medicine $20043512599-2610$.

4 Schram MT, Chaturvedi N, Schalkwijk CG, Fuller JH \& Stehouwer CD. Markers of inflammation are cross-sectionally associated with microvascular complications and cardiovascular disease in type 1 diabetes - the EURODIAB Prospective Complications Study. Diabetologia 2005.

5 Dart AM \& Kingwell BA. Pulse pressure - a review of mechanisms and clinical relevance. Journal of the American College of Cardiology 200137 975-984.

6 Domanski M, Norman J, Wolz M, Mitchell G \& Pfeffer M. Cardiovascular risk assessment using pulse pressure in the first National Health and Nutrition Examination Survey (NHANES I). Hypertension $200138793-797$.

7 Franklin SS, Larson MG, Khan SA, Wong ND, Leip EP, Kannel WB \& Levy D. Does the relation of blood pressure to coronary heart disease risk change with aging? The Framingham Heart Study. Circulation 2001103 1245-1249.

8 Benetos A, Rudnichi A, Safar M \& Guize L. Pulse pressure and cardiovascular mortality in normotensive and hypertensive subjects. Hypertension $1998 \mathbf{3 2} 560-564$.

9 Ronnback M, Fagerudd J, Forsblom C, Pettersson-Fernholm K, Reunanen A \& Groop PH. Altered age-related blood pressure pattern in type 1 diabetes. Circulation $20041101076-1082$.

10 Schram MT, Chaturvedi N, Fuller JH \& Stehouwer CD. Pulse pressure is associated with age and cardiovascular disease in type 1 diabetes: the Eurodiab Prospective Complications Study. Journal of Hypertension 200321 2035-2044.

11 Berry KL, Skyrme-Jones RA, Cameron JD, O’Brien RC \& Meredith IT. Systemic arterial compliance is reduced in young patients with IDDM. American Journal of Physiology 1999276 H1839-H1845.

12 Romney JS \& Lewanczuk RZ. Vascular compliance is reduced in the early stages of type 1 diabetes. Diabetes Care 200124 2102-2106.

13 Ryan SM, Waack BJ, Weno BL \& Heistad DD. Increases in pulse pressure impair acetylcholine-induced vascular relaxation. American Journal of Physiology $1995 \mathbf{2 6 8}$ H359-H363.

14 Hensley K, Robinson KA, Gabbita SP, Salsman S \& Floyd RA. Reactive oxygen species, cell signaling, and cell injury. Free Radical Biology and Medicine 200028 1456-1462.

15 Touyz RM. Reactive oxygen species, vascular oxidative stress, and redox signaling in hypertension: what is the clinical significance? Hypertension $2004 \mathbf{4 4} 248-252$.

16 Wolk R, Berger P, Lennon RJ, Brilakis ES, Johnson BD \& Somers VK. Plasma leptin and prognosis in patients with established coronary atherosclerosis. Journal of the American College of Cardiology 200444 1819-1824.

17 Schulze MB, Shai I, Rimm EB, Li T, Rifai N \& Hu FB. Adiponectin and future coronary heart disease events among men with type 2 diabetes. Diabetes $2005 \mathbf{5 4} 534-539$.

18 Goday A, Castell C, Tresserras R, Canela J, Taberner JL \& Lloveras G. Incidence of type 1 (insulin-dependent) diabetes mellitus in Catalonia, Spain. The Catalan Epidemiology Diabetes Study Group. Diabetologia 199235 267-271.

19 Friedewald WT, Levy RI \& Fredrickson DS. Estimation of the concentration of low-density lipoprotein cholesterol in plasma, without use of the preparative ultracentrifuge. Clinical Chemistry $197218499-502$.

20 Eknoyan G, Hostetter T, Bakris GL, Hebert L, Levey AS, Parving HH, Steffes MW \& Toto R. Proteinuria and other markers of chronic kidney disease: a position statement of the National Kidney Foundation (NKF) and the National Institute of Diabetes and Digestive and Kidney Diseases (NIDDK). American Journal of Kidney Diseases $2003 \mathbf{4 2} 617-622$.

21 Feldman EL, Stevens MJ, Thomas PK, Brown MB, Canal N \& Greene DA. A practical two-step quantitative clinical and electrophysiological assessment for the diagnosis and staging of diabetic neuropathy. Diabetes Care 199417 1281-1289.

22 Perkins BA, Olaleye D, Zinman B \& Bril V. Simple screening tests for peripheral neuropathy in the diabetes clinic. Diabetes Care $200124250-256$.

23 Vinik AI, Maser RE, Mitchell BD \& Freeman R. Diabetic autonomic neuropathy. Diabetes Care 200326 1553-1579.

24 Vespasiani G, Bruni M, Meloncelli I, Clementi L, Amoretti R, Branca S, Carinci F, Lostia S, Nicolucci A, Romagnoli F, Verga S \& Benedetti MM. Validation of a computerised measurement system for guided routine evaluation of cardiovascular autonomic neuropathy. Computer Methods and Programs in Biomedicine 1996 $51211-216$.

25 Diez-Ruiz A, Tilz GP, Zangerle R, Baier-Bitterlich G, Wachter H \& Fuchs D. Soluble receptors for tumour necrosis factor in clinical laboratory diagnosis. European Journal of Haematology 199554 1-8.

26 Benjafield AV, Wang XL \& Morris BJ. Tumor necrosis factor receptor 2 gene (TNFRSF1B) in genetic basis of coronary artery disease. Journal of Molecular Medicine 200179 109-115.

27 Van Greevenbroek MM, Van Der Kallen CJ, Geurts JM, Janssen RG, Buurman WA \& De Bruin TW. Soluble receptors for tumor necrosis factor-alpha (TNF-R p55 and TNF-R p75) in familial combined hyperlipidemia. Atherosclerosis $2000 \mathbf{1 5 3} 1-8$.

28 Mitchell GF \& Pfeffer MA. Pulsatile hemodynamics in hypertension. Current Opinion in Cardiology $199914361-369$.

29 Chappell DC, Varner SE, Nerem RM, Medford RM \& Alexander RW. Oscillatory shear stress stimulates adhesion molecule expression in cultured human endothelium. Circulation Research $1998 \mathbf{8 2} 532-539$.

30 Baumann $\mathrm{H} \&$ Gauldie J. The acute phase response. Immunology Today $19941574-80$.

31 Abramson JL, Weintraub WS \& Vaccarino V. Association between pulse pressure and C-reactive protein among apparently healthy US adults. Hypertension 200239 197-202.

32 Cesari M, Penninx BW, Newman AB, Kritchevsky SB, Nicklas BJ, Sutton-Tyrrell K, Tracy RP, Rubin SM, Harris TB \& Pahor M. Inflammatory markers and cardiovascular disease (the Health Aging and Body Composition [Health ABC] Study). American Journal of Cardiology $200392522-528$.

33 Fernandez-Real JM \& Ricart W. Insulin resistance and chronic cardiovascular inflammatory syndrome. Endocrine Reviews 2003 24 278-301.

34 Fernandez-Real JM, Gutierrez C, Ricart W, Castineira MJ, Vendrell J \& Richart C. Plasma levels of the soluble fraction of tumor necrosis factor receptors 1 and 2 are independent determinants of plasma cholesterol and LDL-cholesterol concentrations in healthy subjects. Atherosclerosis $1999146321-327$.

35 Samad F, Uysal KT, Wiesbrock SM, Pandey M, Hotamisligil GS \& Loskutoff DJ. Tumor necrosis factor alpha is a key component in the obesity-linked elevation of plasminogen activator inhibitor 1. PNAS $1999966902-6907$.

36 Avolio A. Pulse pressure and inflammatory markers. Journal of Hypertension 200422 247-249.

Received 8 April 2005

Accepted 28 July 2005 